\title{
Highly Active Antiretroviral Therapy Alters Sperm Parameters and Testicular Antioxidant Status in Diet-Induced Obese Rats
}

\author{
Ibukun P. Oyeyipo ${ }^{1,2}$, Bongekile T. Skosana' ${ }^{1}$ Frans P. Everson' ${ }^{1}$, Hans Strijdom ${ }^{1}$ and Stefan S. du \\ Plessis $^{1}$ \\ 'Division of Medical Physiology, Department of Biomedical Sciences, Faculty of Medicine and Health Sciences, \\ Stellenbosch University, Tygerberg, South Africa \\ ${ }^{2}$ Department of Physiology, College of Health Sciences, Osun State University, Osogbo, Osun State, Nigeria
}

\begin{abstract}
The efficacy of highly active antiretroviral therapy (HAART) has led to an increase demand for therapeutic use, thereby necessitating investigation into drug toxicity. This study was designed to investigate the in vivo effects of HAART on sperm parameters and testicular oxidative stress in lean and obese rats. Wistar rats (males, $\mathrm{n}=40$, weighing 180 200 g) were assigned randomly into 4 groups and treated accordingly for 16 weeks as follows: Control (C): lean group fed with standard rat chow; Diet induced obesity (DIO): obese animals fed a high caloric diet; C + ART: lean animals treated with HAART; DIO + ART: obese animals treated with HAART. An antiretroviral drug combination of Tenofovir, Emtricitabine and Efavirenz at a dose of 17, 26 and $50 \mathrm{mg} / \mathrm{kg} / \mathrm{day}$ was administered for the latter 6 weeks via jelly cube feeding. At the end of the experimental period, sperm analysis was performed on sperm collected from the caudal epididymis, while the testis was homogenized for antioxidant enzyme and lipid peroxidation assays. Results showed that HAART significantly decreased sperm motility $(p<0.05)$ in both lean and obese animals, and viability $(p<0.05)$ in the DIO group. Testicular glutathione, catalase and superoxide dismutase were significantly decreased $(p<0.05)$, while Thiobarbituric acid reactive substances (TBARS) levels were significantly increased $(p<0.05)$ when the DIO+ART group was compared to Control group. Thus, the decreased sperm qualities associated with HAART might be as a result of increased testicular oxidative stress prominent in obese animals.
\end{abstract}

Key words: Highly active antiretroviral therapy, Obesity, Sperm, Motility, Velocity, Testicular antioxidants

\section{INTRODUCTION}

The human immunodeficiency virus/acquired immunodeficiency syndrome (HIV/AIDS) epidemic has emerged as a major global challenge affecting all ages, races, and sexes. Highly active antiretroviral therapy (HAART) is considered the most effective treatment for individuals with HIV-1 infection. This therapy is a combination of

Correspondence to: Stefan S. du Plessis, Division of Medical Physiology, Faculty of Medicine and Health Sciences, Stellenbosch University, P. O. Box 241, Cape Town, 8000, South Africa E-mail: ssdp@sun.ac.za

This is an Open-Access article distributed under the terms of the Creative Commons Attribution Non-Commercial License (http:// creativecommons.org/licenses/by-nc/3.0) which permits unrestricted non-commercial use, distribution, and reproduction in any medium, provided the original work is properly cited. two or more antiretroviral drugs, usually nucleoside/nucleotide reverse transcriptase inhibitors (NRTIs) and protease inhibitors (PIs) or non-nucleoside reverse transcriptase inhibitors (NNRTIs). A first-line, anti-HIV, fixed drug combination containing tenofovir (TDF), emtricitabine (FTC), and efavirenz (EFV), which combines two NRTIs (TDF and FTC) and an NNRTI (EFV), has been recommended for the treatment of patients with HIV infection and has resulted in superior outcomes compared with other fixeddose treatments (1).

Generally, HAART has been associated with a reduction in the morbidity and mortality attributable to HIVinduced immune deficiency (2). With the advent of HAART, there has been a dramatic improvement in overall prognosis, with appreciable impact on the management of HIV infection, reduction in viral replication, and increased hope of parenthood for HIV patients (3-5). HAART has also 
demonstrated remarkable success in reducing the overall health care costs for people who are HIV-positive $(6,7)$.

Despite the numerous beneficial effects of HAART, studies have revealed a number of side effects, clinical adverse events, and toxicities. Clinical adverse effects associated with HAART include AIDS-related insulin resistance, hyperglycemia, and gastrointestinal and lipodystrophy symptoms $(8,9)$, whereas the most common toxicity associated with NRTIs and NNRTIs is hepatotoxicity, which is usually due to damage to mitochondria $(10,11)$.

HIV infection is most common among individuals of reproductive age and approximately one-third of those affected desire to raise children. Therefore, reproductive effects have emerged as clinically important issues in patients with HIV infection (5). Alterations in reproductive physiology have been responsible for subfertility in women infected with HIV-1 (5) and direct gonadal failure has been associated with HIV infection in both sexes. Little attention has been paid to the effects of HAART on male gametes, but relevant studies have indicated that HIV-1-infected men undergoing HAART experience alterations in semen parameters (12). However, another study showed no alterations in semen parameters (13). In a prospective study, Van Leeuwen et al. (14) highlighted the adverse effects of HAART on sperm motility. These were attributed to the damaging effect of these treatments on the mitochondria, which are the power houses of the cell and play important roles in sperm motility. HAART has also been associated with a reduction in ejaculate volume, increase in abnormal sperm morphology, and reduced potential to fertilize an oocyte $(15,16)$. However, these findings are debatable because it is difficult to separate the role of the HIV infection from the effect of treatment. Animal studies indicated that four weeks of treatment with nevirapine caused degeneration of the seminiferous tubules, necrosis of the spermatids, and defoliation of spermatocytes (17).

Obesity is a public health issue that affects both children and adults (18). It has been associated with the combination of an increasingly sedentary lifestyle and an unfavorable diet. A study carried out on the epidemic of obesity among HIV patients revealed that two-thirds of HIV patients in the studied cohort were overweight or obese, a proportion that is similar to that among healthy people living without HIV infection. This indicated that the obesity epidemic also involves the HIV population (19).

Despite the growing knowledge of the effects of HAART on male reproduction, there are contradictory findings with respect to objective sperm functional tests and antioxidant status and it is currently unclear if HAART has a different impact in those who are obese. The availability of the different classes and combinations of antiretroviral drugs is a further cause of concern because it is presumed that different drug combinations can possibly have dissim- ilar effects on biological systems. To the best of our knowledge, no study has investigated the effect of this specific, first-line, anti-HIV fixed drug combination containing TDF, FTC, and EFV on male reproductive parameters. The present study was therefore designed to investigate the effect of combining TDF, FTC, and EFV on male sperm parameters and testicular antioxidant status in lean and dietinduced obese rats.

\section{MATERIALS AND METHODS}

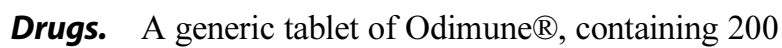
mg emtricitabine (FTC), $300 \mathrm{mg}$ tenofovir disoproxil fumarate (TDF), and $600 \mathrm{mg}$ efavirenz (EFV) and produced by CIPLA MEDPRO (PTY) LTD (South Africa), was purchased from commercial sources.

Study design. Forty inbred male Wistar rats (180 $200 \mathrm{~g}$ ) were used for this study. Animals were randomly divided into 4 experimental groups ( $n=10$ /group) with no differences in body weight (BW) between the 4 groups prior to onset of the experiment. They had free access to food and water and were kept on a $12 \mathrm{hr}$ day/night cycle in an AAALAC (Association for the Assessment and Accreditation of Laboratory Animal Care International) accredited facility for 16 weeks. Obesity was induced and maintained in animals by feeding them a high calorie diet (20). The experimental groups were as follows: control (C), lean group fed with standard rat chow; diet induced obesity (DIO), obese animals fed a high caloric diet; C + ART, lean animals treated with HAART; DIO + ART, obese animals treated with HAART. HAART administration commenced at week 10 and continued through week 16 of the experimental period. Treatment consisted of a once daily, fixed dose combination of TDF, FTC, and EFV. The drugs were ground into a powder, weighed, and added to jelly cubes of $1 \mathrm{~mL}$ volume. These were then administered according to the BW of each rat. The untreated groups received an equal volume of jelly cubes without the drug. Treatment administration was conducted according to the Food and Drug Administration (FDA) standards for human to rat conversion, which was six times the dose for human per $\mathrm{kg}$ for rat as follows: EFV, $50 \mathrm{mg} / \mathrm{kg} /$ day; FTC, $17 \mathrm{mg} / \mathrm{kg} /$ day; and TDF, $26 \mathrm{mg} / \mathrm{kg} / \mathrm{day}$. At the end of week 16, animals were anaesthetized with pentobarbital $(160 \mathrm{mg} / \mathrm{kg})$ until deep anesthesia was reached as evidenced by the lack of a pedal reflex. They were then euthanized by exsanguination before tissue collection for further analysis. The study received ethical clearance (SU-ACUM13-00025) from the committee for the ethical use of animals in research at the Faculty of Medicine and Health Sciences, Stellenbosch University and conformed to the Guide for the Care and Use of Laboratory Animals of the NIH (Publication No. 85-23, revised 1996). 
Anthropometric measurements. The BW of the animals was monitored throughout the experimental period. Blood was obtained via a tail prick and fasting blood glucose levels were determined using a conventional glucometer (Cipla MedPro, Bellville, South Africa). The visceral fat mass, testes, and epididymes were excised, weighed, and preserved appropriately.

Sperm analysis. The cauda epididymis of each rat was placed in $5 \mathrm{~mL}$ of HAMS F10 supplemented with 3\% BSA (Roche Diagnostics GmbH Mannheim, Germany) and cut into several fragments to allow the spermatozoa to swim out from the epididymal lumen. Sperm analysis was carried out on sperm suspensions obtained from the 4 groups. The quality of sperm was assessed based on its viability, motility, and velocity parameters. Sperm motility and velocity parameter analysis was performed with computer-aided sperm analysis (CASA) using a Sperm Class Analyser (SCA ${ }^{\circledR}$; Microptic, Barcelona, Spain). A $2 \mu \mathrm{L}$ sample was loaded into a pre-warmed eight-chamber standard count analysis slide (Leja products, GN Nieuw-Vennep, The Netherlands) at $37^{\circ} \mathrm{C}$ and analyzed. The system analyzed the total motility and velocity parameters, including curvilinear velocity (VCL), straight line velocity (VSL), average path velocity (VAP), amplitude of lateral head displacement (ALH), and beat cross-frequency (BCF). Sperm viability was determined using the eosin (EO) dye exclusion test. Briefly, the sperm suspension was mixed thoroughly and $10 \mu \mathrm{L}$ of the suspension was mixed with $20 \mu \mathrm{L}$ of eosin and $30 \mu \mathrm{L}$ of nigrosin dye. A thin smear was prepared after $1 \mathrm{~min}$, allowed to air-dry, and coverslipped. The number of viable sperm was determined after the counting of 100 spermatozoa (in duplicate) at $\times 100$ magnification under oil immersion in a blinded fashion (21). The live spermatozoa were unstained and the dead sperm were stained red, thereby indicating a damaged membrane. Results were expressed as \% viable cells.

\section{Biochemical assays.}

- Glutathione (GSH) status analysis: The testicular total GSH was measured according to the method described by Asensi et al (22). Briefly, testicular tissue samples were homogenized $(1: 10)$ in $15 \%(\mathrm{w} / \mathrm{v})$ trichloroacetic acid containing $1 \mathrm{mM}$ EDTA for GSH determination and in $6 \%$ (v/v) perchloric acid containing freshly prepared $3 \mathrm{mM} \mathrm{1-}$ methyl-2-vinylpyridinium and $1 \mathrm{mM}$ ethylenediaminetetraacetic acid for GSH determination on ice. After centrifugation at $10,000 \mathrm{~g}$ for $10 \mathrm{~min}, 50 \mu \mathrm{L}$ of supernatant (testicular homogenate) was added to $50 \mu \mathrm{L}$ of GSH reductase $(1 \mathrm{U})$ and $50 \mu \mathrm{L}$ of $0.3 \mathrm{mM} \mathrm{5,5'-dithiobis-2-nitrobenzoic}$ acid. The reaction was initiated by the addition of $1 \mathrm{mM}$ NADPH to a final volume of $200 \mu \mathrm{L}$. The change in absorbance was monitored at $410 \mathrm{~nm}$ for $5 \mathrm{~min}$ and levels were calculated using pure GSH as the standard.
- Superoxide dismutase: The activity of testicular superoxide dismutase (SOD) was determined according to the method of Crosti et al (24). Briefly, the reaction mixture in a 96-well plate consisted of $15 \mu \mathrm{L}$ of sample, 170 $\mu \mathrm{L}$ of $0.1 \mathrm{mM}$ DETAPAC in $50 \mathrm{mM}$ sodium phosphate buffer (pH 7.4), and $20 \mu \mathrm{L}$ of $1.6 \mathrm{mM}$ 6-hydroxydopamine, which initiated the reaction. The reaction was measured at $490 \mathrm{~nm}$ for $4 \mathrm{~min}$ at $30 \mathrm{~s}$ intervals and SOD activity was expressed as $\mathrm{U} / \mathrm{mg}$ of protein.

- Catalase (CAT): CAT activity in the testicular homogenates was determined using the method described by Aebi (23). Briefly, $5 \mu \mathrm{L}$ of sample and $170 \mu \mathrm{L}$ of $50 \mathrm{mM}$ potassium phosphate $(\mathrm{pH} 7.0)$ were added to a clear 96-well plate, followed by $50 \mu \mathrm{L}$ of $0.1 \%$ hydrogen peroxide $\left(\mathrm{H}_{2} \mathrm{O}_{2}\right)$ in $50 \mathrm{mM}$ potassium phosphate ( $\mathrm{pH} 7.0$ ) to initiate the reaction. The rate of decomposition of $\mathrm{H}_{2} \mathrm{O}_{2}$ was measured at $240 \mathrm{~nm}$ for $2 \mathrm{~min}$ in $15 \mathrm{~s}$ intervals using a Multiskan Spectrum plate reader (Thermo Fisher Scientific, USA). CAT activity ( $\mu \mathrm{mol} \mathrm{H}_{2} \mathrm{O}_{2}$ consumed $/ \mathrm{min} / \mu \mathrm{g}$ protein) was determined using the molar extinction coefficient of 43.6.

- Estimation of thiobarbituric acid reacting substances (TBARS): Testicular lipid peroxidation products were estimated by determining TBARS, a product of lipid oxidation. TBARS were measured on a plate reader according to a method modified from that of Khoschsorur et al (25). Fifty microliters of testicular homogenates was mixed with $375 \mu \mathrm{L}$ of $0.44 \mathrm{M} \mathrm{H}_{3} \mathrm{PO}_{4}$ and $125 \mu \mathrm{L}$ of $42 \mathrm{mM}$ aqueous 2-thiobarbituric acid, then $225 \mu \mathrm{L}$ of distilled water was added. The mixture was heated in boiling-water in a water bath for $60 \mathrm{~min}$. After cooling on ice, alkaline methanol $(5 \mathrm{~mL}+45 \mathrm{~mL} 1 \mathrm{M} \mathrm{NaOH})$ was added to the reaction mixture in a $1: 1$ ratio. The samples were centrifuged for $3 \mathrm{~min}$ and absorbance was read at $535 \mathrm{~nm}$ using a micro plate reader.

Statistical analyses. The data are presented as mean \pm SEM and were analyzed using one-way analysis of variance (ANOVA) followed by Bonferroni's multiple comparison test, which was performed using GraphPad Prism version 5.00 for Windows (GraphPad Software, San Diego, CA, USA). A result of $p<0.05$ was considered statistically significant.

\section{RESULTS}

Effects of HAART on BW, organ weight, peritoneal fat, and plasma glucose. The BW of all animals increased significantly during the research period; however, all animals in the DIO group gained significantly more weight than their counterparts (Table 1). The final BW of the DIO group was significantly higher than that of the $\mathrm{C}$ group $(436.6 \mathrm{~g} \pm 15.11$ vs. $347.40 \mathrm{~g} \pm 12.10 ; p<0.05)$ and the final $\mathrm{BW}$ of the animals in the DIO+ART group was significantly higher than that of the animals in the $\mathrm{C}+\mathrm{ART}$ 
Table 1. Body and visceral fat weights during the experimental period

\begin{tabular}{llcccc}
\hline \hline & & \multicolumn{2}{c}{ Body weight } & \multicolumn{2}{c}{ Visceral fat } \\
& \multicolumn{1}{c}{ Initial $(\mathrm{g})$} & \multicolumn{1}{c}{ Final $(\mathrm{g})$} & Absolute difference $(\mathrm{g})$ & Percentage change $(\%)$ & $(\mathrm{g})$ \\
\hline $\mathrm{C}$ & $303.90 \pm 9.67$ & $347.40 \pm 12.10$ & $43.50 \pm 6.05$ & $14.31 \pm 2.42$ & $13.14 \pm 2.10$ \\
DIO & $390.50 \pm 10.43^{*}$ & $436.60 \pm 15.11^{*}$ & $46.10 \pm 8.36$ & $11.81 \pm 5.64$ & $25.84 \pm 2.81^{*}$ \\
$\mathrm{C}+$ ART & $305.40 \pm 11.32$ & $350.40 \pm 13.09$ & $45.00 \pm 5.76$ & $14.74 \pm 3.19$ & $12.01 \pm 2.32$ \\
DIO + ART & $392.40 \pm 8.10^{*^{+}}$ & $440.70 \pm 11.10^{*^{+}}$ & $48.30 \pm 5.06$ & $12.31 \pm 3.20$ & $27.29 \pm 3.10^{*^{+}}$ \\
\hline
\end{tabular}

Initial = weight prior to onset of HAART treatment (week 10), Final = weight after being on 6 weeks diet and HAART treatment (week 16), \% difference $=$ Absolute difference/Initial $B W \times 100$.

Data are expressed as mean \pm SEM $(n=10)$.

${ }^{*} p<0.05$ : compared to $C$. ${ }^{+} p<0.05$ : compared to $\mathrm{C}+\mathrm{ART}$.

Table 2. Organ weight and plasma glucose levels of the experimental groups

\begin{tabular}{llcccc}
\hline \hline Groups & $\begin{array}{c}\text { Testicular } \\
\text { weight }(\mathrm{g})\end{array}$ & $\begin{array}{c}\text { Epididymal } \\
\text { weight }(\mathrm{g})\end{array}$ & $\begin{array}{c}\text { Relative testicular } \\
\text { weight }(\%)\end{array}$ & $\begin{array}{c}\text { Relative epididymal } \\
\text { weight }(\%)\end{array}$ & $\begin{array}{c}\text { Fasting glucose } \\
(\mathrm{mmol} / \mathrm{L})\end{array}$ \\
\hline C & $3.37 \pm 0.10$ & $1.45 \pm 0.05$ & $0.97 \pm 0.05$ & $0.42 \pm 0.03$ & $5.30 \pm 0.80$ \\
DIO & $2.97 \pm 0.11^{*}$ & $1.39 \pm 0.06$ & $0.68 \pm 0.07$ & $0.32 \pm 0.02$ & $5.30 \pm 0.91$ \\
C + ART & $3.30 \pm 0.09$ & $1.31 \pm 0.03$ & $0.94 \pm 0.04$ & $0.37 \pm 0.03$ & $5.37 \pm 0.81$ \\
DIO + ART & $2.88 \pm 0.1 *^{*^{+}}$ & $1.35 \pm 0.03$ & $0.65 \pm 0.08$ & $0.31 \pm 0.02$ & $5.38 \pm 0.91$ \\
\hline
\end{tabular}

Relative testicular weight $=$ Testicular weight/Body weight $\times 100$, Relative epididymal weight $=$ Epididymal weight/Body weight $\times 100$. Data are expressed as mean \pm SEM $(n=10)$.

${ }^{*} p<0.05$ : compared to $C .{ }^{+} p<0.05$ : compared to $\mathrm{C}+\mathrm{ART}$.

Table 3. Sperm analysis in the experimental groups

\begin{tabular}{lllcccc}
\hline \hline Groups & \multicolumn{1}{c}{ Viability $(\%)$} & Total motility $(\%)$ & VCL $(\mu \mathrm{m} / \mathrm{s})$ & VSL $(\mu \mathrm{m} / \mathrm{s})$ & ALH $(\mu \mathrm{m} / \mathrm{s})$ & BCF $(\mathrm{Hz})$ \\
\hline C & $84.00 \pm 7.32$ & $82.14 \pm 7.60$ & $185.00 \pm 10.09$ & $47.88 \pm 3.42$ & $11.40 \pm 1.23$ & $3.60 \pm 0.50$ \\
DIO & $73.86 \pm 6.26^{*}$ & $71.56 \pm 6.81^{*}$ & $173.56 \pm 14.42$ & $45.61 \pm 3.98$ & $8.86 \pm 1.10^{*}$ & $2.50 \pm 0.23$ \\
C + ART & $83.29 \pm 6.43$ & $63.01 \pm 4.91^{*}$ & $176.23 \pm 12.61$ & $46.79 \pm 4.89$ & $6.38 \pm 1.30^{*}$ & $1.65 \pm 0.30^{*}$ \\
DIO + ART & $52.43 \pm 5.08^{* *+}$ & $50.23 \pm 4.76^{*++}$ & $136.62 \pm 10.76^{*++}$ & $41.85 \pm 3.11^{*}$ & $4.22 \pm 1.90^{* *}$ & $1.72 \pm 0.43^{* *}$ \\
\hline
\end{tabular}

$\mathrm{VCL}=$ curvilinear velocity; $\mathrm{VSL}=$ straight line velocity, $\mathrm{ALH}=$ amplitude of lateral head displacement; $\mathrm{BCF}=$ beat cross frequency. Data are expressed as mean \pm SEM $(n=10)$.

${ }^{*} p<0.05$ : compared to $C$. \#p<0.05: compared to DIO. ${ }^{+} p<0.05$ : compared to $C+$ ART.

group (440.70 $\mathrm{g} \pm 11.10 \mathrm{vs.} 350.40 \mathrm{~g} \pm 13.09 ; p<0.05)$ and that of the $\mathrm{C}$ group $(440.70 \mathrm{~g} \pm 11.10$ vs. $347.40 \mathrm{~g} \pm$ $12.10 ; p<0.05)$. HAART treatment did not induce any significant BW changes in the respective dietary groups; however, there was a comparable BW gain and percentage BW gain in all experimental groups.

Visceral fat mass was higher in the DIO group than in the $\mathrm{C}$ group ( $25.84 \mathrm{~g} \pm 2.81$ vs. $13.14 \mathrm{~g} \pm 2.10 ; p<0.05)$. Visceral fat mass was also higher in the DIO + ART group than in the $\mathrm{C}+$ ART group $(27.29 \mathrm{~g} \pm 3.10$ vs $12.01 \mathrm{~g} \pm$ $2.32 ; p<0.05)$. The differences in visceral fat mass in the $\mathrm{C}$ vs. $\mathrm{C}+\mathrm{ART}$ and in the $\mathrm{DIO}$ vs. DIO + ART were comparable (Table 1).

Treatment with HAART resulted in significantly reduced testicular tissue of obese animals in the DIO + ART group compared with that in the DIO group $(2.88 \mathrm{~g} \pm 0.10 \mathrm{vs}$. $2.97 \pm 0.11, p<0.05)$. A decrease in testicular weight was also observed between obese and lean animals (Table 2). No differences were observed in epididymal weight or rel- ative testicular and epididymal weight. Similarly, no differences were observed in the fasting blood glucose levels among any of the four groups (Table 2).

Effect of HAART on sperm parameters. The viability of spermatozoa significantly decreased after obese animals received HAART treatment (DIO vs. DIO + ART: $73.86 \pm 6.26 \%$ vs. $52.43 \pm 5.08 \%, p<0.05)$. Obesity per se also significantly reduced sperm viability, as indicated by the comparison between the $\mathrm{C}$ and DIO groups $(84.00 \pm$ $7.32 \%$ vs. $73.86 \pm 6.26 \%, p<0.05)$ and that between the $\mathrm{C}+\mathrm{ART}$ and DIO + ART groups $(83.29 \pm 6.43 \%$ vs. $52.43 \pm$ $5.08 \%, p<0.05$ ) (Table 3 ). The reported values regarding the margin of change observed due to the combinations and treatment indicated that the combination of obesity and HAART negatively impacted the percentage of viable cells (Table 3 ).

There was a significant decrease in sperm motility when that from the $\mathrm{C}$ group was compared with that from the 
$\mathrm{C}+$ ART group $(82.14 \pm 7.60 \%$ vs. $63.01 \pm 4.91 \%, p<0.05)$ and when that from the DIO group was compared with that from the DIO + ART group $(71.56 \pm 6.81 \%$ vs. $50.23 \pm$ $4.76 \%, p<0.05)$. We also observed that obesity impaired motility when the $\mathrm{C}$ group was compared with the DIO group $(82.14 \pm 7.60 \%$ vs. $71.56 \pm 6.81 \%, p<0.05)$ and the $\mathrm{C}+\mathrm{ART}$ group was compared with the DIO + ART group $(63.01 \pm 4.91 \%$ vs. $50.23 \pm 4.76 \%, p<0.05)$. Interestingly, the greatest percentage reduction in motility was observed when HAART treatment was combined with obesity (Table 3).

Various kinematic and velocity parameters were also affected by obesity (ALH), HAART alone (ALH, BCF), and the combination of obesity and HAART (VCL, VSL, ALH, BCF), as shown in Table 3.

Effects of HAART on oxidative stress. Administration of HAART caused a significant decrease $(p<0.05)$ in testicular GSH concentration as indicated by the significant difference between GSH levels in the $\mathrm{C}$ and $\mathrm{C}+\mathrm{ART}$ groups $(74.50 \pm 3.90$ vs. $38.67 \pm 4.28 \mu \mathrm{g} / \mathrm{mg}$ protein, $p<$ $0.05)$ and that between the DIO and DIO + ART groups $(50.17 \pm 4.18$ vs. $18.83 \pm 1.85 \mu \mathrm{g} / \mathrm{mg}$ protein, $p<0.05)$. Obesity also reduced testicular GSH concentrations significantly, based on the comparison between the $\mathrm{C}$ and DIO groups $(74.50 \pm 3.9$ vs. $50.17 \pm 4.18 \mu \mathrm{g} / \mathrm{mg}$ protein, $p<0.05)$ and the $\mathrm{C}+\mathrm{ART}$ and $\mathrm{DIO}+\mathrm{ART}$ groups
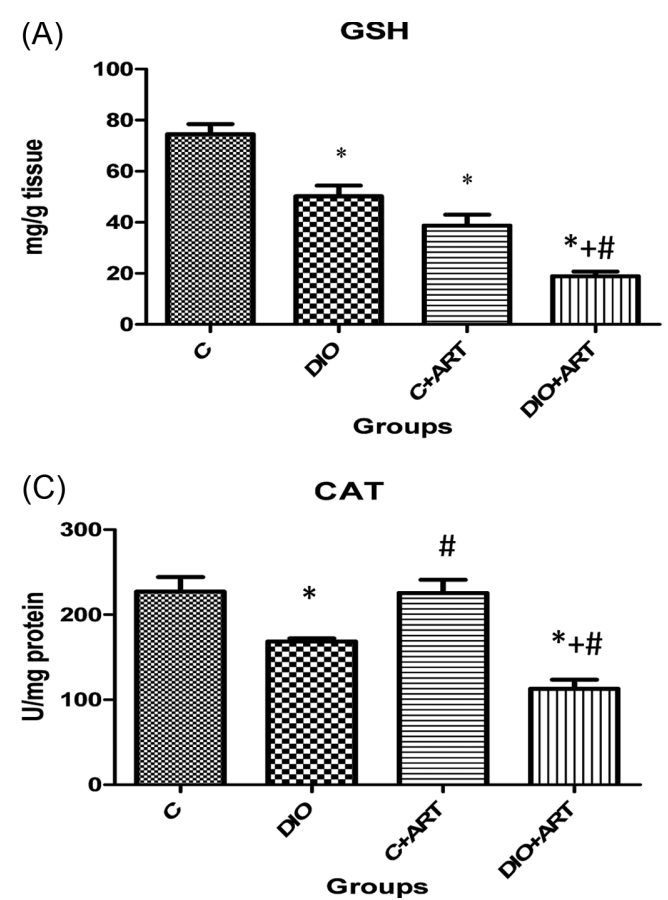

$(38.67 \pm 4.28$ vs. $18.83 \pm 1.85 \mu \mathrm{g} / \mathrm{mg}$ protein, $p<0.05)$ (Fig. 1A). Similarly, SOD (7.92 \pm 0.16 vs. $6.23 \pm 0.23 \mu \mathrm{g} /$ mg protein, $p<0.05)$ and CAT $(168.55 \pm 4.61$ vs. $112.80 \pm$ $10.94 \mu \mathrm{g} / \mathrm{mg}$ protein, $p<0.05)$ activities also decreased in only the obese animals after HAART treatment (Fig. 1B, 1C). HAART treatment had no effect on these two metalloprotein antioxidant enzymes in the lean animals. Lipid peroxidation, as measured by the TBARS level, significantly $(p<0.05)$ increased in the DIO + ART group compared with that in the $\mathrm{C}+$ ART group (Fig. 1D) and in the $\mathrm{C}$ group compared with that in the DIO group $(2.06 \pm 0.01$ vs $2.22 \pm 0.02 \mu \mathrm{mol} / \mathrm{mg}$ protein, $p<0.05$ ).

\section{DISCUSSION}

The introduction of HAART in the management of HIV has improved therapeutic outcomes by reducing mortality and morbidity. However, this therapy has a number of challenging pitfalls, probably due to associated drug-drug interactions, organ specific toxicity, and non-adherence. There is paucity of information in the literature regarding the adverse effects of HAART on male reproductive function and the probable mechanisms underlying the harmful reproductive effects. We report for the first time that HAART consisting of TDF, FTC, and EFV has spermatotoxic effects associated with elevated lipid peroxidation products and concomitant reduction in testicular antioxi-

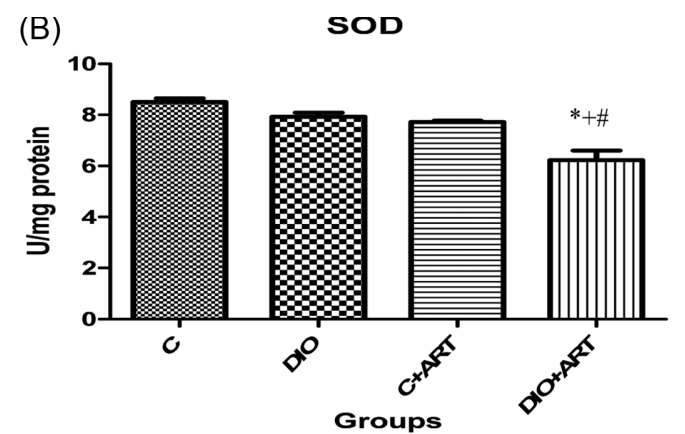

(D)

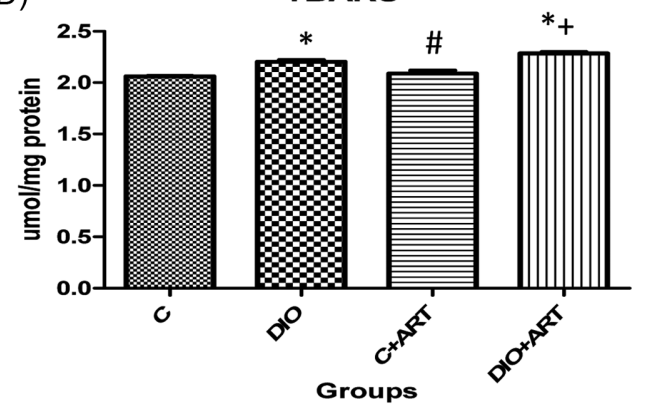

Fig. 1. (A) Glutathione concentration levels in testicular tissue of HAART-treated Wistar rats. (B) Superoxide dismutase activity levels in testicular tissue of HAART-treated Wistar rats. (C) Catalase activity levels in testicular tissue of HAART-treated Wistar rats. (D) Lipid peroxidation (TBARS) levels in testicular tissue of HAART-treated Wistar rats. Bars indicate the mean \pm SEM $(n=10) .{ }^{*} p<0.05$ : compared to $\mathrm{C}$. $\# p<0.05$ : compared to DIO. ${ }^{+} p<0.05$ : compared to $\mathrm{C}+\mathrm{ART}$. 
dant status in both lean and obese rats. It is well known that oxidative stress results from the imbalances between antioxidants and free radicals. The cells are generally protected from oxidative stress by enzymatic (CAT, SOD) and non-enzymatic (GSH) complex antioxidant systems (26). Oxidative stress has been reported to be one of the most important causes of male infertility and has been associated with altered sperm function and steroidogenic capacity. It impairs the ability of LH to activate the steroidogenic acute regulatory (StAR) protein-catalyzed transport of cholesterol from the outer mitochondrial membrane to the inner mitochondrial membrane, which is a rate-limiting step in steroid biosynthesis (27).

The significant increase in final BW and visceral fat mass observed in the DIO group was an indication that obesity was successfully induced by the diet. Sperm motility and viability are important features of fertile spermatozoa. These attributes are dependent on an adequate energy supply and a jealously-guarded polyunsaturated fatty acid membrane susceptible to oxidative stress mediated damage (28).

The results indicated that total sperm motility decreased significantly in both groups of HAART-treated animals. The observed decrease in sperm parameters in the DIO group was similar to that in previous studies, which showed that obesity was associated with reduced total sperm motility in rats $(29,30)$. In addition, our data indicated that HAART caused decreased sperm motility because even in lean mice, a decrease in motility was observed. However, it is worth noting that the decrease in motility ascribed to HAART was more pronounced in the obese group. An earlier study also associated HAART, consisting of zidovudine, lamivudine, and nevirapine, with reduced sperm motility in rats (28), whereas TDF, when used in isolation, was previously reported to have spermiostatic activity (31). The decrease in VCL, ALH, and BCF values of spermatozoa observed in this study showed that HAART adversely influenced the swimming pattern of spermatozoa and consequently had a negative effect on fertility potential, whereas obesity aggravated the adverse effect. In addition, it is important to note that these parameters are markers of sperm vigor, cervical mucus penetration, and effective rate of fertilization necessary as the sperm travels through the female reproductive tract to fertilize the oocyte $(32,33)$. The decreases in VCL and BCF in the DIO group treated with HAART correlated with the significant reduction in sperm viability because these parameters have been linked with the viability of the sperm $(34,35)$.

The increased visceral fat in the DIO + ART group might have also contributed to the adverse reproductive effects observed in this group. Previous reports indicated that increased fat deposition compromised the efficacy of thermoregulation, reduced the radiation of heat, increased the generation of reactive oxygen species (ROS), and promoted the development of oxidative stress in reproductive organs, ultimately resulting in reduced sperm quality (3638). The observed increase in lipid peroxidation, evidenced by an increase in the level of TBARS in the testicular tissue, was similar to earlier findings that associated increased oxidative stress with HIV treatment (39). The decrease in GSH levels might have contributed to an increase in lipid peroxidation because GSH is an antioxidant that reacts directly with free radicals in non-enzymatic reactions and protects cells against a variety of different ROS. Similarly, the significant decrease in the activity of SOD and CAT in the groups treated with HAART suggested an inability of their testicular tissue to inactivate/dismutase $\mathrm{O}_{2}^{-}$and/or eliminate $\mathrm{H}_{2} \mathrm{O}_{2}$, thereby leading to an accumulation of these highly reactive radicals within the testicular tissue. The possibility of depletion of CAT owing to an increase in $\mathrm{H}_{2} \mathrm{O}_{2}$ as a result of a corresponding decrease in enzyme activity during HAART metabolism cannot be ruled out. The observed decrease in sperm parameters might have been caused by the increased lipid peroxidation within the testis because destruction of the structure of the lipid matrix in the spermatozoa plasma membrane leads to loss of intracellular ATP, resulting in decreased sperm motility and viability. The decrease in testicular SOD activity may have been a result of decreased de novo synthesis of enzyme proteins or inactivation of these enzyme proteins, leading to a decrease in function (40).

Lipid peroxidation of unsaturated fatty acids is often used as an indicator of oxidative stress and oxidative damage (41). The increased TBARS concentration might have been due to a decreased production of antioxidants in the HAART-treated rat tissues, thereby shifting the delicate balance in favor of ROS and leading to a plethora of pathologic damage to sperm cells, including lipid peroxidation and concomitant loss of function. This study further indicated that down-regulation of antioxidant enzyme levels in the treated rats was a mechanism by which HAART induced infertility in the male rat, possibly because of mitochondrial damage caused by HAART, which is a source of oxidative radicals, as was reported in other organs $(10,11)$. We therefore concluded that HAART altered sperm parameters through increased testicular oxidative stress by decreasing the concentration and activity of antioxidants and obesity, caused by a high calorie diet, exacerbated these adverse effects. Further studies are recommended to evaluate to what extend these effects translate into infertility and the potential of utilizing exogenous antioxidants, such as such as Vitamin C or E, with HAART therapies.

\section{ACKNOWLEDGMENTS}

The authors are grateful to the Faculty of Medicine and Health Sciences, University of Stellenbosch for the post- 
doctoral fellowship awarded of the first author and also to the Harry Crossley Foundation (South Africa) for funding this research.

\section{CONFLICT OF INTEREST}

None declared by all authors.

Received July 17, 2017; Revised September 1, 2017; Accepted September 7, 2017

\section{REFERENCES}

1. Pozniak, A.L., Gallant, J.E., DeJesus, E., Arribas, J.R., Campo, R.E., Chen, S.S., McColl, D., Enejosa, J., Toole, J.J. and Cheng, A.K. (2006) Tenofovir disoproxil fumarate, emtricitabine, and efavirenz versus fixed-dose zidovudine/ lamivudine and efavirenz in antiretroviral-naive patients: virologic, immunologic, and morphologic changes--a 96week analysis. J. Acquir. Immune Defic. Syndr., 43, 535-540.

2. Palella, F.J., Jr., Delaney, K.M., Moorman, A.C., Loveless, M.O., Fuhrer, J., Satten, G.A., Aschman, D.J. and Holmberg, S.D. (1998) Declining morbidity and mortality among patients with advanced human immunodeficiency virus infection. HIV outpatient study investigators. N. Engl. J. Med., 338, 853-860.

3. Bujan, L., Sergerie, M., Moinard, N., Martinet, S., Porte, L., Massip, P., Pasquier, C. and Daudin, M. (2007) Decreased semen volume and spermatozoa motility in HIV-1-infected patients under antiretroviral treatment. J. Androl., 28, 444452.

4. Kayode, A.A., Kayode, O.T., Aroyeun, O.A. and Stephen, M.C. (2011) Hematologic and hepatic enzyme alterations associated with acute administration of antiretroviral drugs. J. Pharmacol. Toxicol., 6, 293-302.

5. Kushnir, V.A. and Lewis, W. (2011) Human immunodeficiency virus/acquired immunodeficiency syndrome and infertility: emerging problems in the era of highly active anti- retrovirals. Fertil Steril., 96, 546-553.

6. Mocroft, A., Ledergerber, B., Katlama, C., Kirk, O., Reiss, P., d'Arminio Monforte, A., Knysz, B., Dietrich, M., Phillips, A.N. and Lundgren, J.D. (2003) Decline in the AIDS and death rates in the EuroSIDA study: an observational study. Lancet, 362, 22-29.

7. Crum, N.F., Riffenburgh, R.H., Wegner, S., Agan, B.K., Tasker, S.A., Spooner, K.M., Armstrong, A.W., Fraser, S. and Wallace, M.R. (2006) Comparisons of causes of death and mortality rates among HIV-infected persons: analysis of the pre-, early, and late HAART (highly active antiretroviral therapy) eras. J. Acquir. Immune Defic. Syndr., 41, 194-200.

8. Hagmann, M. (2003) Study confirms effectiveness of antiretroviral drugs for HIV patients. Bull. World Health Organ., 81, 918-919.

9. Montessori, V., Press, N., Harris, M., Akagi, L. and Montaner, J.S. (2004) Adverse effects of antiretroviral therapy for HIV infection. CMAJ, 170, 229-238.

10. Abrescia, N., D’Abbraccio, M., Figoni, M., Busto, A., Madd- aloni, A. and De Marco, M. (2005) Hepatotoxicity of antiretroviral drugs. Curr. Pharm. Des., 11, 3697-3710.

11. Soriano, V., Puoti, M., Garcia-Garsco, P., Rockstroh, J.K., Benhamou, Y., Barreiro, P. and McGovern, B. (2008) Antiretroviral drugs and liver injury. AIDS, 22, 1-13.

12. Bujan, L., Hollander, L., Coudert, M., Gilling-Smith, C., Vucetich, A., Guibert, J., Vernazza, P., Ohl, J., Weigel, M., Englert, Y. and Semprini, A.E. (2007) Safety and efficacy of sperm washing in HIV-1-serodiscordant couples where the male is infected: results from the European CREAThE network. AIDS, 21, 1909-1914.

13. Krieger, J.N., Coombs, R.W., Collier, A.C., Koehler, J.K., Ross, S.O., Chaloupka, K., Murphy, V.L. and Corey, L. (1991) Fertility parameters in men infected with human immunodeficiency virus. J. Infect. Dis., 164, 464-469.

14. van Leeuwen, E., Wit, F.W., Repping, S., Eeftinck Schattenkerk, J.K., Reiss, P., van der Veen, F. and Prins, J.M. (2008) Effects of antiretroviral therapy on semen quality. AIDS, 22, 637-642.

15. Nicopoullos, J.D., Almeida, P., Vourliotis, M., Goulding, R. and Gilling-Smith, C. (2010) A decade of sperm washing: clinical correlates of successful insemination outcome. Hum. Reprod., 25, 1869-1876.

16. Ahmad, G., Moinard, N., Jouanolou, V., Daudin, M., Gandia, P. and Bujan, L. (2011) In vitro assessment of the adverse effects of antiretroviral drugs on the human male gamete. Toxicol. In Vitro, 25, 485-491.

17. Adaramoye, O.A., Adesanya, O.A., Adewumi, O.M. and Akanni, O. (2012) Studies on the toxicological effect of nevirapine, an antiretroviral drug, on the liver, kidney and testis of male Wistar rats. Hum. Exp. Toxicol., 31, 676-685.

18. Du Plessis, S.S., Cabler, S., McAlister, D.A., Sabanegh, E. and Agarwal, A. (2010) The effect of obesity on sperm disorders and male infertility. Nat. Rev. Urol., 7, 153-161.

19. Crum-Cianflone, N., Tejidor, R., Medina, S., Barahona, I. and Ganesan, A (2008) Obesity among patients with HIV: the latest epidemic. AIDS Patient Care STDS, 22, 925-930.

20. Pickavance, L.C., Tadayyon, M., Widdowson, P.S., Buckingham, R.E. and Wilding, J.P. (1999) Therapeutic index for rosiglitazone in dietary obese rats: separation of efficacy and haemodilution. Br. J. Pharmacol., 128, 1570-1576.

21. Eliasson, R. (1977) Supravital staining of human spermatozoa. Fertil. Steril., 28, 1257.

22. Asensi, M., Sastre, J., Pallardó, F.V., Lloret, A., Lehner, M., Garcia-de-la-Asunción, J. and Viña, J. (1999) Ratio of reduced to oxidized glutathione as indicator of oxidative stress status and DNA damage. Methods Enzymol., 299, 267-276.

23. Aebi, H. (1984) Catalase in vitro. Meth. Enzymol., 105, 121126.

24. Crosti, N., Servidei, T., Bajer, J. and Serra, A. (1987) Modification of the 6-hydroxydopamine technique for the correct determination of superoxide dismutase. J. Clin. Chem. Clin. Biochem., 25, 265-266.

25. Khoschsorur, G.A., Winklhofer-Raab, B.M., Rabl, H., Aue, T.H., Peng, Z. and Schau, R.J. (2000) Evaluation of a sensitive HPLC method for the determination of malondialdehyde, and application of the method to different biological materials. Chromatographia, 52, 181-184.

26. Van Antwerpen, P.V. and Nève, J. (2004) In vitro compara- 
tive assessment of the scavenging activity against three reactive oxygen species of non-steroidal anti-inflammatory drugs from the oxicam and sulfoanilide families. Eur. J. Pharmacol., 496, 55-61.

27. Aitken, R.J. and Roman, S.D. (2008) Antioxidant systems and oxidative stress in the testes. Oxid. Med. Cell. Longev., 1, 15-24.

28. Ogedengbe, O.O., Jegede, A.I., Onanuga, I.O., Offor, U., Naidu, E.C., Peter, A.I. and Azu, O.O. (2016) Coconut oil extract mitigates testicular injury following adjuvant treatment with antiretroviral drugs. Toxicol. Res., 32, 317-325.

29. Oyeyipo, I.P., Maartens, P.J. and du Plessis, S.S. (2015) Diet-induced obesity alters kinematics of rat spermatozoa. Asian Pac. J. Reprod., 4, 235-239.

30. Fernandez, C.D., Bellentani, F.F., Fernandes, G.S., Perobelli, J.E., Favareto, A.P., Nascimento, A.F., Cicogna, A.C. and Kempinas, W.D. (2011) Diet-induced obesity in rats leads to a decrease in sperm motility. Reprod. Biol. Endocrinol., 9, 32.

31. Ospina, L., Álvarez-Gómez, A., Cadavid, A. and CardonaMaya, W. (2011) Tenofovir, an antiviral agent with low spermiostatic activity. Actas Urol. Esp., 35, 123-124.

32. Liu, J., Liang, C., Yin, C., Wang, T., Li, H., Li, Y. and Ye, Z. (2004) Effects of several Chinese herbal aqueous extracts on human sperm motility in vitro. Andrologia, 36, 78-83.

33. Martini, A.C., Tissera, A., Estofan, D., Molina, R.I., Arnaldo, M., de cuneo, M.F. and Ruiz, R.D. (2010) Overweight and seminal quality: a study of 794 patients. Fertil. Steril., 94, 1739-1743.

34. Donnelly, E.T., Lewis, S.E.M., McNally, J.A. and Thomp- son, W. (1998) In vitro fertilization and pregnancy rates: the influence of sperm motility and morphology on IVF outcome. Fertil. Steril., 70, 305-314.

35. Duty, S.M., Calafat, A.M., Silva, M.J., Brock, J.W., Ryan, L., Chen, Z., Overstreet, J. and Hauser, R. (2004) The relationship between environmental exposure to phthalates and computer-aided sperm analysis motion parameters. $J$. Androl., 25, 293-302.

36. Banks, S., King, S.A., Irvine, D.S. and Saunders, P.T. (2005) Impact of a mild scrotal heat stress on DNA integrity in murine spermatozoa. Reproduction, 129, 505-514.

37. Ivell, R. (2007) Lifestyle impact and the biology of the human scrotum. Reprod. Biol. Endocrinol., 5, 15.

38. Perez-Crespo, M., Pintado, B. and Gutierrez-Adan, A. (2008) Scrotal heat stress effects on sperm viability, sperm DNA integrity, and the offspring sex ratio in mice. Mol. Reprod. Dev., 75, 40-47.

39. Hulgan, T., Morrow, J., D’Aquila, R.T., Raffanti, S., Morgan, M., Rebeiro, P. and Haas, D.W. (2003) Oxidant stress is increased during treatment of human immunodeficiency virus infection. Clin. Infect. Dis., 37, 1711-1717.

40. McCord, J.M., Keele, B.B., Jr. and Fridovich, I. (1971) An enzyme-based theory of obligate anaerobiosis: The physiological function of superoxide dismutase. Proc. Natl. Acad. Sci. U.S.A., 68, 1024-1027.

41. Khatibi, F., Yaghoubi, A.R. and Rahbani, N.M. (2012) Study of antioxidant enzymes, lipid peroxidation, lipid profile and immunologic factor in coronary artery disease in East Azarbijan. Int. J. Med. Biomed. Res., 1, 147-152. 